\title{
Data Management Documentation
}

National Cancer Institute

\section{Source}

National Cancer Institute. Data Management Documentation. NCI Thesaurus. Code C115682.

Records pertaining to the management, acquisition, validation, storage, protection, and processing of data. 